\title{
Thermal Control System for Space Station Freedom Photovoltaic Power Module
}

(NASA-TM-105650) THERMAL CONTROL N94-24825 SYSTEM FOR SPACE STATION FREEDOM PHOTOVOLTAIC POWER MODULE (NASA) $13 \mathrm{p}$ $13 P$

Thomas H. Hacha National Aeronautics and Space Administration Lewis Research Center Cleveland, Ohio

and

Laura Howard Rockwell International Canoga Park, California

Prepared for the 22nd International Conference on Environmental System sponsored by the Society of Automotive Engineers Seattle, Washington, July 13-16, 1992 
$F-7$ 


\title{
Thermal Control System for Space Station Freedom Photovoltaic Power Module
}

\author{
Thomas $\mathrm{H}$. Hacha \\ National Aeronautics and Space Administration \\ Lewis Research Center \\ Cleveland, Ohio 44135 \\ and \\ Laura S. Howard \\ Rockwell International \\ Rocketdyne Division \\ Canoga Park, California 91303
}

\section{ABSTRACT}

The electric power for Space Station Freedom (SSF) is generated by the solar arrays of the photovoltaic power modules (PVM's) and conditioned, controlled, and distributed by a power management and distribution system. The PVM's are located outboard of the alpha gimbals of SSF. A single-phase thermal control system is being developed to provide thermal control of PVM electrical equipment and energy storage batteries. This system uses ammonia as the coolant and a direct-flow deployable radiator. This paper presents the description and development status of the PVM thermal control system.

\section{INTRODUCTION}

The electric power system for Space Station Freedom (SSF) provides utility grade power to the user interface via a modular and expandable network of power generation, energy storage, control, and distribution equipment. This system is being developed by Rockwell International Rocketdyne Division under contract with NASA Lewis Research Center. The power system uses 160-Vdc electrical buses for the primary distribution of power and converts it to $120-\mathrm{Vdc}$ secondary distribution power for the user interface. It also provides 28 -Vdc power to the space shuttle.

All of the SSF electric power is generated by photovoltaic power modules (PVM's), which provide

direct and stored energy at $160 \mathrm{Vdc}$ to the central station for distribution to the users. The thermal conditioning of the electrical equipment and the energy - storage systems in the PVM is provided by both active and passive thermal control systerns.

This paper describes the active thermal control system being developed to thermally control the PVM electrical equipment and energy storage batteries. The system is located outboard of the port and starboard alpha gimbals on SSF and separate from the inboard active thermal control system. A PVM and the locations of the three PVM's on SSF are shown In Fig. 1.

\section{PHOTOVOLTAIC POWER MODULE (PVM)}

The SSF at permanently manned configuration is equipped with three PVM's: two on the starboard side and one on the port side. Each PVM has a rated capacity of $18.75 \mathrm{~kW}$ average and $25 \mathrm{~kW}$ peak. This represents a rated capacity of $56.25 \mathrm{~kW}$ average and $75 \mathrm{~kW}$ peak at permanently manned configuration.

The major subassemblies of the PVM are two beta gimbal/photovoltaic array assemblies and the integrated equipment assembly (IEA). The beta gimbal/ photovoltaic array assemblies convert radiant energy from the sun into dc electric power, which is supplied to SSF through the IEA. The IEA conditions and stores the electric power collected by the photovoltaic arrays for use in SSF operations. The PVM thermal control system heat acquisition, heat transport, and heat rejection (radiator) systems are part of the IEA.

\section{PHOTOVOLTAIC POWER MODULE THERMAL CONTROL SYSTEM}

The PVM thermal control system (TCS) acquires excess heat from the energy storage (batteries) and electrical equipment assemblies located on the IEA and transports this heat to a dedicated radiator for rejection to space. The TCS is a single-phase system that uses ammonia as the coolant. All fluid-handling surfaces are constructed with corrosion-resistant stainless steel, which provides excellent material compatibility with ammonia. The TCS maintains the battery cell temperatures between 0 and $10^{\circ} \mathrm{C}$, and the electrical equipment baseplate temperature below $41^{\circ} \mathrm{C}$. All of the heat-generating sources cooled by the TCS are orbital replacement units (ORU's) located on the IEA. These ORU's, their basic functions, maximum heat generation rates, and quantity are listed in Table $\mathrm{l}$. Although heat loads vary throughout each orbit, the TCS is designed 
to reject an orbital average heat load of approximately $7.5 \mathrm{~kW}$.

The major assemblies and components in the PVM thermal control system are (1) the pump and flow control subassemblies (PFCS's), which are orbital replacement units located on the IEA, (2) a direct-flow deployable radiator subassembly, which is an ORU attached to the IEA structural framework, (3) radiant fin heat exchangers (RFX's) and associated fluid tubing which are located within the IEA structural framework, and (4) fluid quick disconnects (FQD's), which connect fluid lines from the IEA tubing to the PFCS and radiator.

Figure 2 shows the IEA and the location of the heat source ORU's (batteries, dc switching units (DCSU's), battery charge and discharge units (BCDU's), and dc-to-dc converter units (DDCU's)), the PFCS's, and the radiator in the stowed position.

A flow schematic of the PVM thermal control system is shown in Fig. 3. This schematic is for the first PVM launch, which has redundant PFCS's on the IEA for failure tolerance requirements. Subsequent PVM launches will have a single PFCS. Single-phase ammonia liquid coolant is pumped by one of the two pumps in the PFCS at a constant flow rate of approximately $1180 \mathrm{~kg} / \mathrm{hr}$ to the fluid lines in the IEA. Heat is acquired via radiant fin heat exchangers (RFX's) from the batteries, BCDU's, DCSU's, and DDCU's by a parallel-series flow anrangement. After heat acquisition the fluid flows through one of the two redundant flow loops in the radiator, where heat is radiated to space. The redundant flow loops in the radiator are activated and deactivated by the radiator FQD isolation valves. After heat rejection the fluid is returned to the PFCS and recirculated. A flow control valve in the PFCS varles the flow through the radiator via a bypass while maintaining nearly constant flow to the RFX's in the IEA. Battery cell temperatures are maintained within their prescribed range by circulating more flow through the radiator during high heat loads and less flow through the radiator during low heat loads. Fluid accumulators located in the PFCS and the radiator allow fluid expansion and contraction over the TCS operating temperature range and maintain system pressure above saturation pressure. FQD's connect and disconnect the PFCS and radiator fluid lines to the IEA during ORU replacement. A FQD is also used for coolant filling and draining of the system. Both the accumulators and the FQD's are used to facilitate leak detection and isolation.

COLDPLATE SUBASSEMBLIES - The TCS system collects heat via a unique application of fin, heat sink, and heat exchanger technology. One unusual feature of this design is that the heat-sink-like baseplate of the energy storage subsystem (batteries and BCDU) and electrical equipment (DCSU and DDCU) ORU's transfer excess heat by mechanism of radiation rather than the traditional mechanism of convection from the fins. This radiant heat is then received by the finned heat exchanger subassemblies that make up the TCS coldplate subassemblies. The coldplate subassemblies serve as components of the TCS as well as structural members of the IEA structural framework. Each coldplate assembly consists of two or more radiant fin heat exchanger subassemblies. Each heat exchanger subassembly consists of a stainless steel serpentine tube soldered to an aluminum finned plate.

Figure 4 illustrates the RFX thermal interface with a typical ORU. The following heat transfer process occurs during normal operation of the PVM. Heat is generated by the battery cells or other electrical components and is transferred to the ORU box baseplate by conduction. This heat is then transferred to the mating fins of the heat exchanger subassembly by radiation. The fins conduct the heat away, transferring it to the solder material, where it is convectively drawn away by the ammonia coolant in the serpentine lines attached to it.

Each coldplate subassembly consists of two or more RFX's interconnected by manifold tubes. Fluid headers hydraulically connect the manifold tubing of the coldplate assemblies to one another. The remaining components of the TCS are interconnected by interim tubing. A coldplate subassembly for two battery ORU's and a battery charge and discharge unit ORU is illustrated in Fig. 5.

This design was driven by a variety of challenging factors. Although this radiant exchange between fins is not the most efficient thermal design, it is a solution that enables on-orbit maintenance flexibility not possible by conventional means of active cooling. In addition, for optimum manufacturing and heat transfer capabilities, it would have been more common to use the same material for serpentine tube and finplate. However, because the tube material must be compatible with the selected coolant, it was necessary to use a dissimilar metal for the tubing and the finplate. The differences in coefficient of thermal expansion necessitated selection of a solder material with good creep capability.

A producibility sample in the form of a battery RFX was fabricated and tested. Thermal cycling and random vibration testing have exhibited hardware design integrity.

PUMP AND FLOW CONTROL SUBASSEMBLY (PFCS) - The PFCS provides fluid transport for the TCS, regulates flow through the radiator, performs a variety of electrical control and interface functions, and allows for fluid volume changes in the TCS. The major components in the PFCS are two pumps, a flow control valve (FCV), a fluid accumulator, a local data interface (LDI), a signal conditioning interface (SCI), and seven motor controllers. The PFCS is being developed by United Technologies Corporation, Hamilton Standard Division, under contract with Rocketdyne. A diagrami of the PFCS is shown in Fig. 6.

Circulation of the ammonia coolant is provided by one of two identical centrifugal pumps in the PFCS. Each pump is powered by a hermetically sealed $120-$ Vdc canned motor and designed to provide 
approximately $1180 \mathrm{~kg} / \mathrm{hr}$ at a $172-\mathrm{kPa}$ head. Although only one pump is operating, the second pump is provided for reliability requirements. Backflow through the nonoperating pump is prevented by a dual check valve.

The flow control valve is a three-way spool valve that controls the percentage of total system flow through the radiator and radiator bypass. The valve is designed to provide 0 - to 100-percent radiator flow with 100 discrete valve positions. Full motion of the valve is accomplished in 10 sec. Valve contoured ports maintain constant fluid system pressure drop at all positions to maintain nearly constant flow through the RFX's. The flow control valve is actuated by a $28-V d c$ stepper motor. Hermetic sealing of the valve is achieved by a magnetic coupling between the spool and the motor.

Fluid accumulators are provided to accommodate the fluid volumetric changes over a temperature range from -77 to $49^{\circ} \mathrm{C}$ and to insure single-phase operation by maintaining the system pressure above the fluid saturation pressure. In addition to the single accumulator in the PFCS, two accumulators are located in the radiator subassembly (one for each flow loop). The accumulator contains fluid coolant and pressurized nitrogen gas separated by a metal bellows. Fluid volumetric changes caused by system temperature excursions result in bellows motion and compression or expansion of the nitrogen cover gas. During normal operation the system pressure is nominally maintained by the accumulators between 793 and $1550 \mathrm{kPa}$. Fluid inventory is determined by sensing the bellows position. This information is used in system leak detection and isolation, described later.

The local data interface is the data link to the sensors and effectors in the TCS. This interface converts commands from the PVM controller located on the IEA to discrete signals used to control the TCS and provides data to the PVM controller.

The signal conditioning interface provides signal conditioning for the TCS instrumentation, supplies low voltage to the local data interface and FQD motor controllers, and performs control functions to actuate the flow control value.

Seven motor controllers are located in the PFCS. Four controllers located in the FQD controller housing operate the fluid quick disconnects (FQD's) located in the PFCS and radiator. These controllers also provide the mate-demate position status of the FQD's. Three controllers perform the control functions to operate the two pump motors and the flow control valve motor.

RADIATOR SUBASSEMBLY - Heat rejection to space is accomplished by the PVM radiator (PVR). The PVR is a direct-flow deployable radiator that is in the folded (stowed) position during launch in the shuttle and during on-orbit assembly. When the PVM is activated, the radiator is deployed to full extension of approximately $15.2 \mathrm{~m}$ in length. Ammonia coolant flows through tubes located in the radiator panels, transferring heat to the panel surface. A high-emissivity, low- absorptivity coating on the panel surface radiates the waste heat to space. The PVR is being developed by LTV Aerospace and Defense Company, LTV Missiles and Electronics Group, Missiles Division, under contract with Rocketdyne. Figure 7 illustrates the PVR in both the stowed and deployed position.

The PVR has eight 3.56- by $1.98-\mathrm{m}$ panels (approximately $93 \mathrm{~m}^{2}$ of radiating area) to reject the required waste heat at the required operational and environmental conditions. The panels are constructed of an aluminum honeycomb matrix with stainless-steel flow passages that extend across the panel. These stainless-steel flow tubes are connected to inlet and outlet manifolds that extend along the panel edges. To facilitate good thermal conduction, the stainless steel tubes are bonded with a silver-filled epoxy to aluminum extrusions that conduct heat to the panel surface. A radiator panel and manifolds are shown in Fig. 8.

On-orbit deployment of the PVR is accomplished with a scissors-type deployment mechanism. The panels are connected by hinges, and the panel fluid manifolds are connected by flexible metal hoses. The mechanism deploys and retracts using a $120-V d c$ brushless motor and a cable drive system. The deployment system provides the capability of manual deployment and retraction in case of motor failure. In the stowed position, a cinching mechanism is used to secure the panels so that the PVR can withstand launch loads. Decinching prior to deployment and cinching prior to ORU removal is done manually.

The PVR has two independent flow circuits. Each circult contains one fluid accumulator. One circuit is operating while the second circuit is closed to the circulating system by the FQD's. This redundant fluid system helps ensure against loss of the radiator and TCS due to penetration of the fluid lines by micrometeorites or orbital debris. With this redundancy there will be 95-percent probability of not losing heat rejection capability for a period of 10 years.

FLUID QUICK DISCONNECTS (FQD) - Fluid quick disconnect couplings are used to connect and disconnect the fluid lines of the PFCS and radiator ORU's to the fluid lines in the IEA, thereby allowing on-orbit replacement of these ORU's. FQD's are also used to facilitate leak detection and isolation. Each FQD has two independent flow passages operated by a 120-Vdc brush-type motor. Each coupling has two halves: a passive half and an active half. The passive half is fixed to the IEA, whereas the active half, which includes the motor and drive train, is attached to the ORU's. Mating and demating is accomplished automatically or manually by translation of the active half to and from the passive half. Spring-loaded Teflon seals were selected for fluid compatibility and low-temperature survivability. The FQD is being developed by Moog Inc., under contract with Rocketdyne. A FQD is illustrated in Fig. 9.

The FQD's have three discrete positions, as follows: 
(1) Mated - Both active and passive halves are coupled and sealed. Isolation valves in both halves are open to flow.

(2) Engaged - Same as mated except that isolation valves in both halves are closed to flow.

(3) Demated - Isolation valves in both halves are closed to flow, and the halves are separated by motion of active half from passive half.

A unique feature of the FQD design is a replaceable cartridge for the passive halves. This feature allows ground and on-orbit replacement of the passive half seals for routine maintenance or in case of seal leakage. A special tool removes the old cartridge, which contains all the seals and moving parts from the FQD passive half housing, and inserts and secures a new cartridge into the housing. This is accomplished at system pressures with only a minor loss of fluid. Since the IEA fluid lines are of all-welded construction, this FQD maintenance feature greatly enhances the IEA reliability.

LEAK DETECTION AND ISOLATION - The TCS instrumentation used for leak detection and isolation measures pressure, temperature, and accumulator position (Fig. 3). This instrumentation in conjunction with on-orbit software algorithms will be capable of autonomously detecting time-critical coolant leaks during TCS operation. On-orbit leaks will be detected by a temperature-compensated, pressure decay method. Coolant leaks that are not time critical will be detected by ground monitoring personnel. In addition, the software will be capable of isolating leaks by means of TCS instrumentation, FQD's, and accumulators. This technique is limited to leak isolation to the PVR, PFCS, and IEA.

Leak isolation will be performed by using the FQD couplings, which separate the PFCS and the PVR from the IEA. These FQD's will be sequentially commanded to connect or isolate portions of the ammonia fluid in the TCS for isolation purposes. The FQD's are sequenced in such a manner that the IEA is never completely isolated from a TCS accumulator located in the PFCS or the PVR. Electrical inhibits ensure that the IEA will always maintain an open fluid path to an accumulator (a necessary safety requirement to ensure that the IEA does not become overpressurized).

\section{SUMMARY}

The Space Station Freedom (SSF) electric power system provides utility grade power to the user interface. All of the SSF electric power is generated by photovoltaic power modules (PVM's).

The batteries and major electrical equipment located on the PVM are cooled by a single-phase thermal control system (TCS), with ammonia as the coolant. All metal surfaces contacted by the coolant are constructed of corrosion-resistant stainless steel for coolant compatibility. The major components of the TCS are a pump and flow control subassembly (PFCS), a radiator subassembly, radiant fin heat exchangers (RFX's), and fluid quick disconnects (FQD's).

Coolant is circulated through the system by a centrifugal pump. Heat from the batteries and electrical equipment is acquired by the fluid via RFX's and rejected to space by a direct-flow deployable radiator. The TCS maintains the battery cell temperatures between 0 and $10^{\circ} \mathrm{C}$ by controlling the flow through the radiator with a flow control valve that allows fluid to bypass the radiator at low heat loads while maintaining nearly constant flow through the RFX's.

The RFX collects heat by a unique application of fin, heat sink, and heat exchanger technology. The heat sources transfer heat to a finned baseplate by conduction. This heat is transferred to the mating fins of the RFX by radiation, then transferred to the coolant tubes by conduction. This design enables on-orbit equipment replacement flexibility not possible with conventional thermal design.

The PFCS contains redundant purnps, a flow control valve, a fluid accumulator, and various electrical equipment. The centrifugal purnps are designed to provide approximately $1180-\mathrm{kg} / \mathrm{hr}$ flow at a $172-\mathrm{kPa}$ head.

The flow control valve regulates the flow through the radiator to control battery cell temperatures within the required range. Fluid volumetric changes over the temperature range -77 to $49^{\circ} \mathrm{C}$ are accommodated by the accumulator in the PFCS and accumulators in the radiator subassembly. The electrical equipment in the PFCS performs a variety of electrical control and interface functions.

The radiator subassembly is a direct-flow deployable radiator that is in the folded (stowed) position during launch and is deployed when the PVM is activated on-orbit. The radiator has eight panels with approximately $93-\mathrm{m}^{2}$ radiating area. The panels are constructed of an aluminum honeycombed matrix. Onorbit deployment is achieved with a motor-powered scissors-type mechanism. Manual deployment and retraction capability is also provided. The radiator has two Independent flow circuits for protection against loss due to micrometeorites or orbital debris.

Fluid quick disconnects (FQD's) are employed to facilitate on-orbit replacement of the PFCS and radiator. FQD's are also used in the leak detection and isolation method employed for the TCS. A unique feature of the FQD design is a replaceable cartridge, which allows onorbit replacement of the seals and moving parts while maintaining system pressure.

TCS instrumentation in conjunction with on-orbit software algorithms will be capable of autonomously detecting time-critical leaks during TCS operation. Leak detection is accomplished by a temperaturecompensated, pressure decay method. Isolation will be performed by using the FQD isolation feature. 


\section{ACRONYMS}

BAT battery

BCDU battery charge and discharge unit

DCSU dc switching unit

DDCU dc-to-dc converter unit

FCV flow control valve

FQD fluid quick disconnect
IEA integrated equipment assembly

ORU orbital replacement unit

PFCS pump and flow control subassembly

PVM photovoltaic power module

PVR PVM radiator

RFX radiant fin heat exchanger

TCS thermal control system

TABLE I. - ORBITAL REPLACEMENT UNITS (ORU'S) CONTROLLED BY PVM THERMAL CONTROL SYSTEM

\begin{tabular}{|c|c|c|c|}
\hline ORU & $\begin{array}{c}\text { Maximum } \\
\text { heat } \\
\text { generation } \\
\text { per ORU, } \\
W\end{array}$ & $\begin{array}{l}\text { Number } \\
\text { of ORU's } \\
\text { per PVM }\end{array}$ & Function \\
\hline $\begin{array}{l}\text { de Switching unit } \\
\text { (DCSU) }\end{array}$ & 420 & 2 & $\begin{array}{l}\text { Provides transfer of power to } \\
\text { and from various electrical } \\
\text { equipment on PVM and } \\
\text { central station. }\end{array}$ \\
\hline Battery & 1150 & 12 & $\begin{array}{l}\text { Provides energy storage } \\
\text { during insolation period and } \\
\text { power during eclipse period. }\end{array}$ \\
\hline $\begin{array}{l}\text { Battery charge and } \\
\text { discharge unit } \\
\text { (BCDU) }\end{array}$ & 420 & 6 & $\begin{array}{l}\text { Regulates power to and from } \\
\text { batteries. }\end{array}$ \\
\hline $\begin{array}{l}\text { dc-to-dc Converter } \\
\text { unit (DDCU) }\end{array}$ & 545 & 2 & $\begin{array}{l}\text { Converts primary } 160-V d c \\
\text { power to secondary } 120-V d c \\
\text { utility-grade power from PVM } \\
\text { usage. }\end{array}$ \\
\hline
\end{tabular}




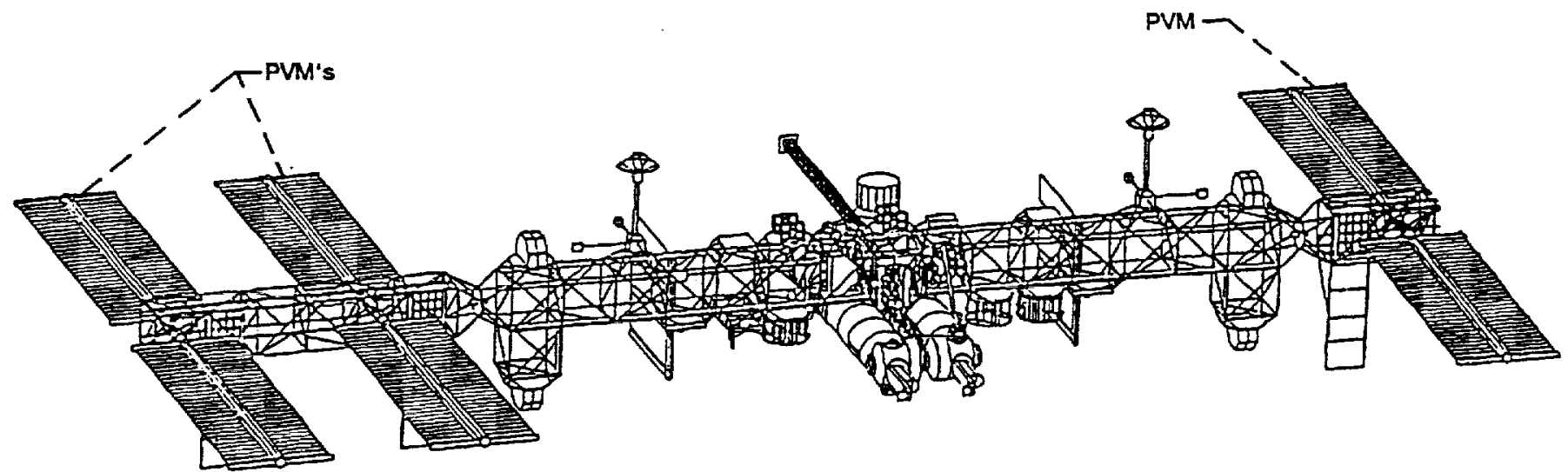

(a) Space Station Freedom permanently manned configuration.

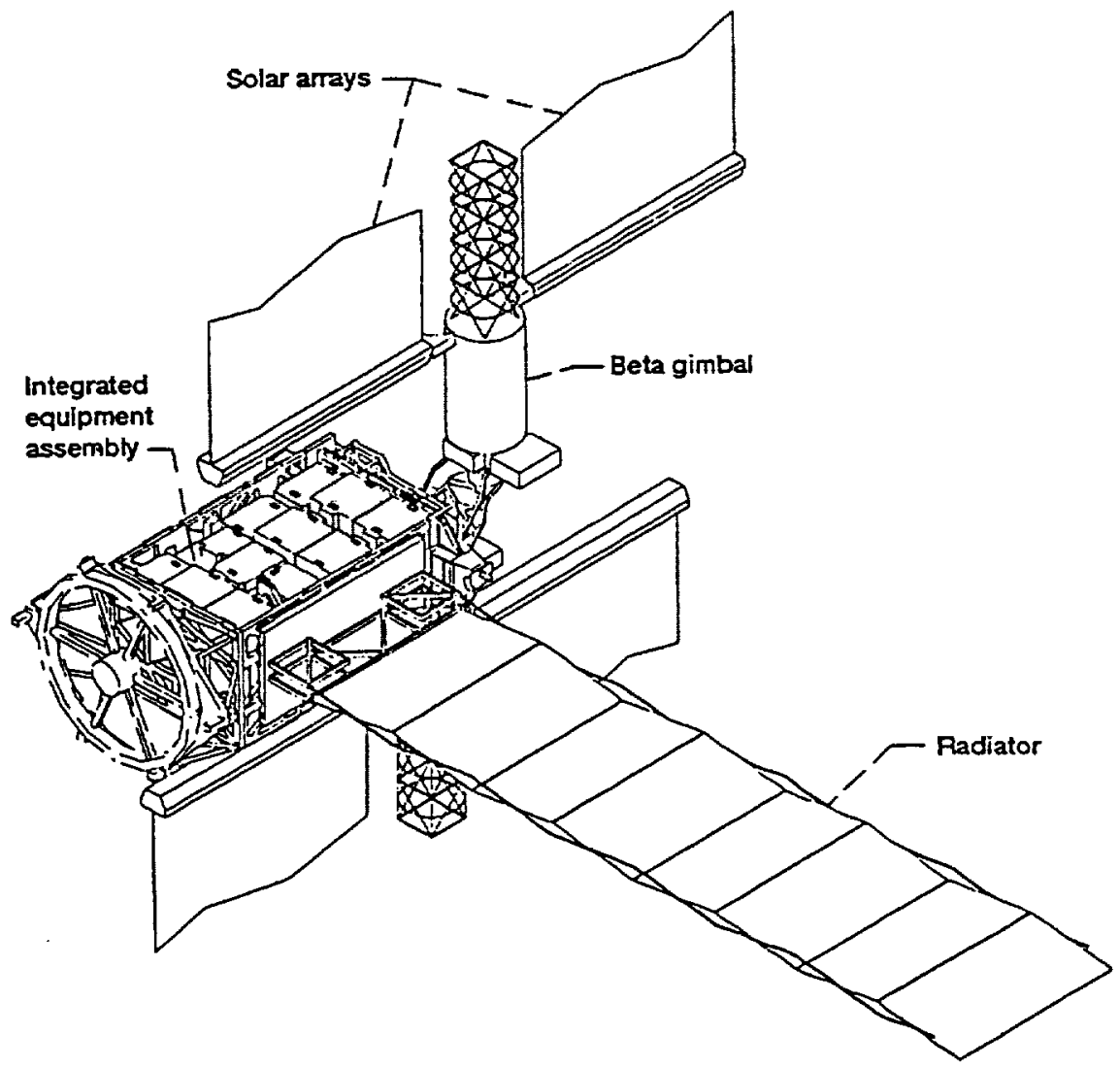

(b) Photovoltaic power module.

Figure 1.- Space Station Freedom and photovoltaic power module. 


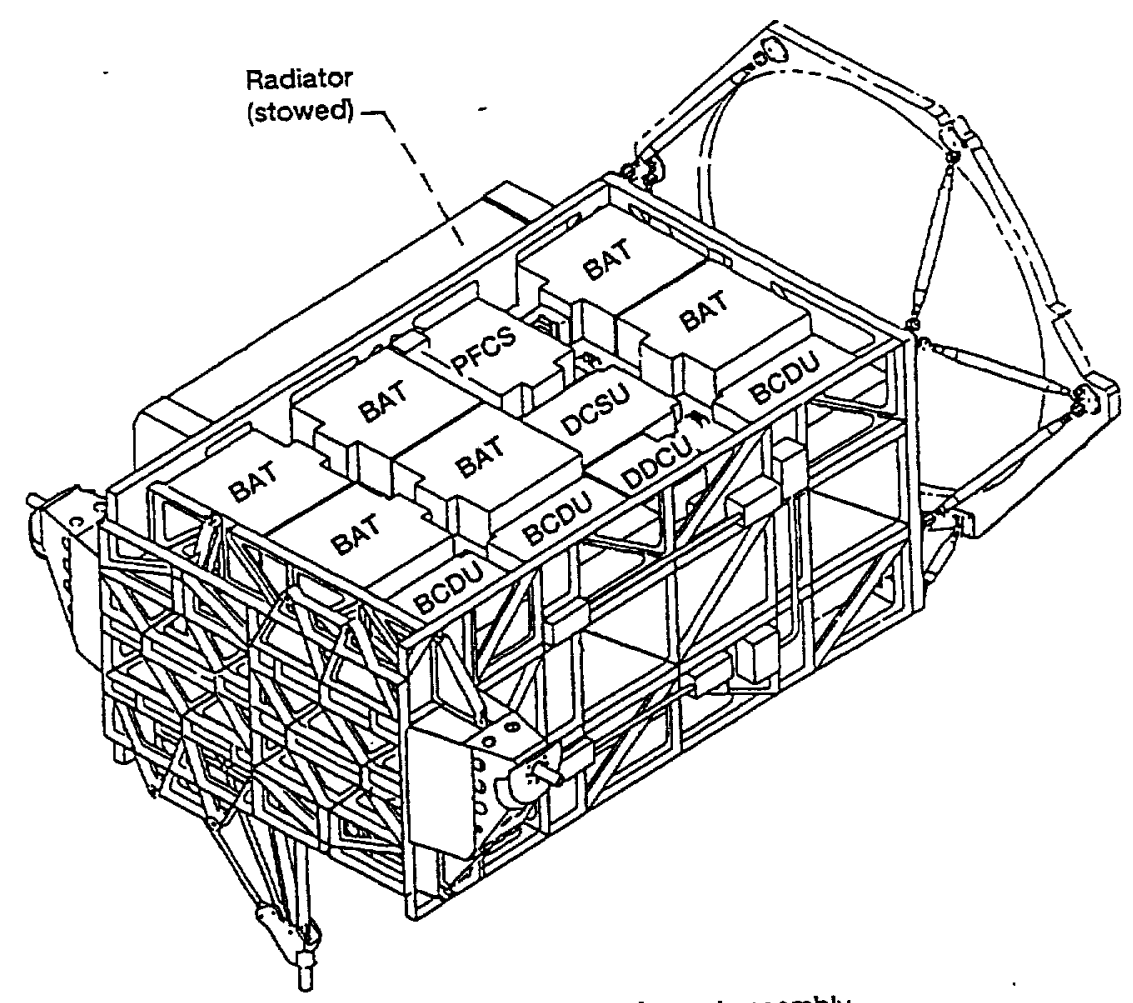

Figure 2.- Integrated equipment assembly.

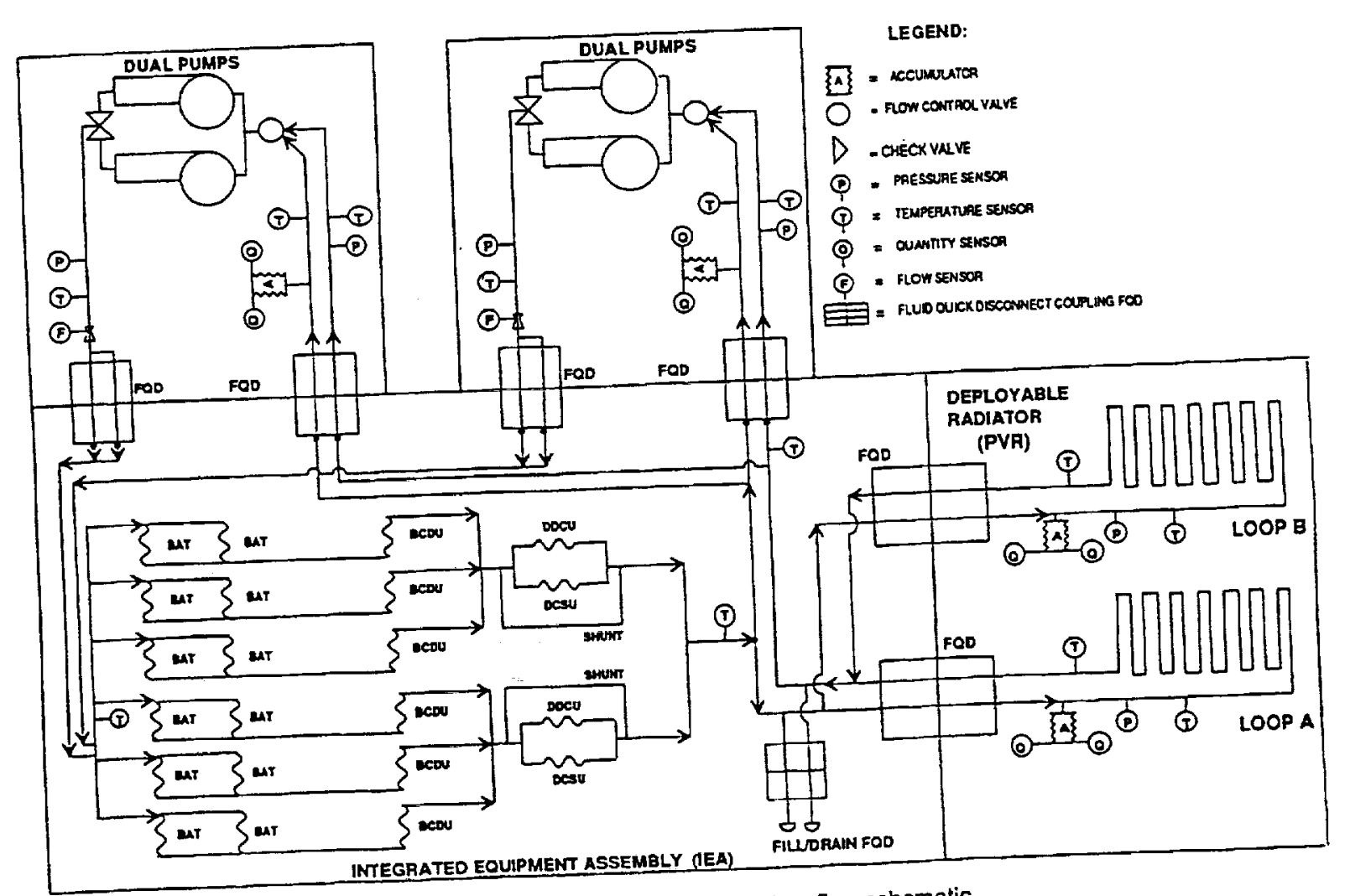

Figure 3.- PVM thermal control system flow schematic. 


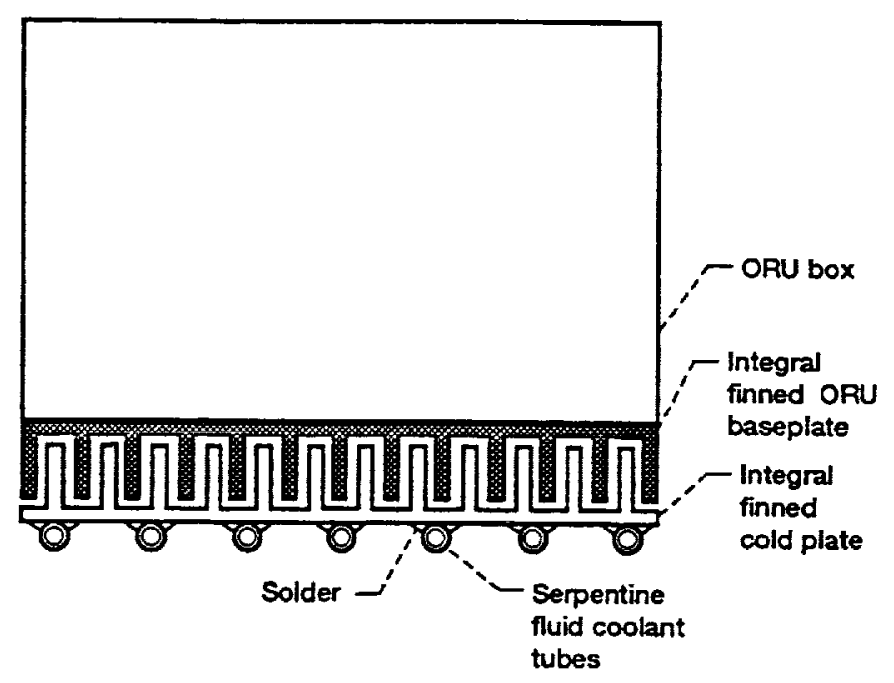

Figure 4.- ORU box radiant heat exchanger interface.

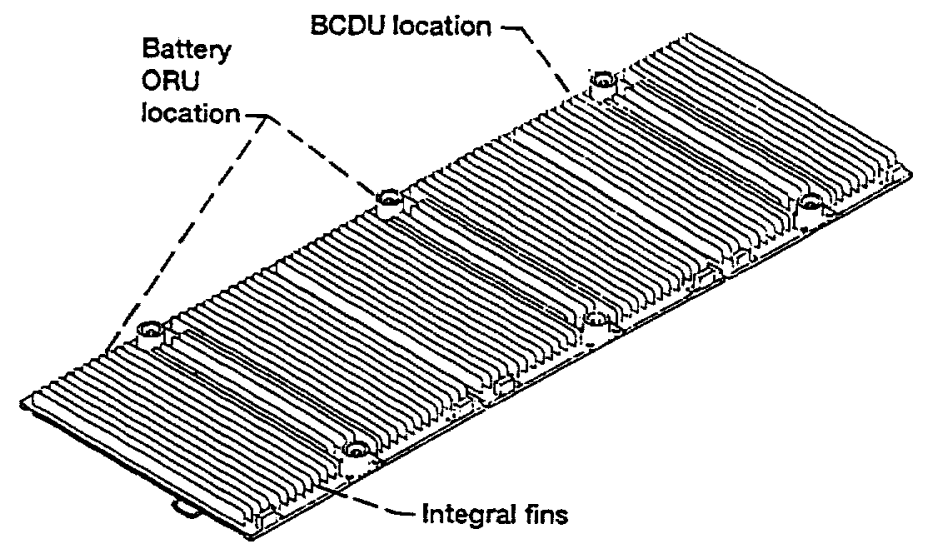

(a) Finned side.

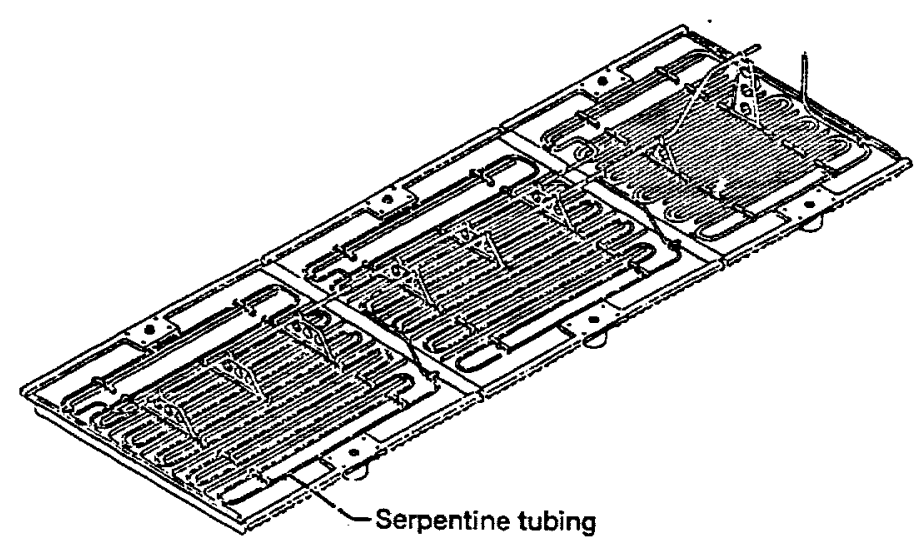

(b) Tube side.

Figure 5.- Cold plate assembly for battery and BCDU ORU's. 


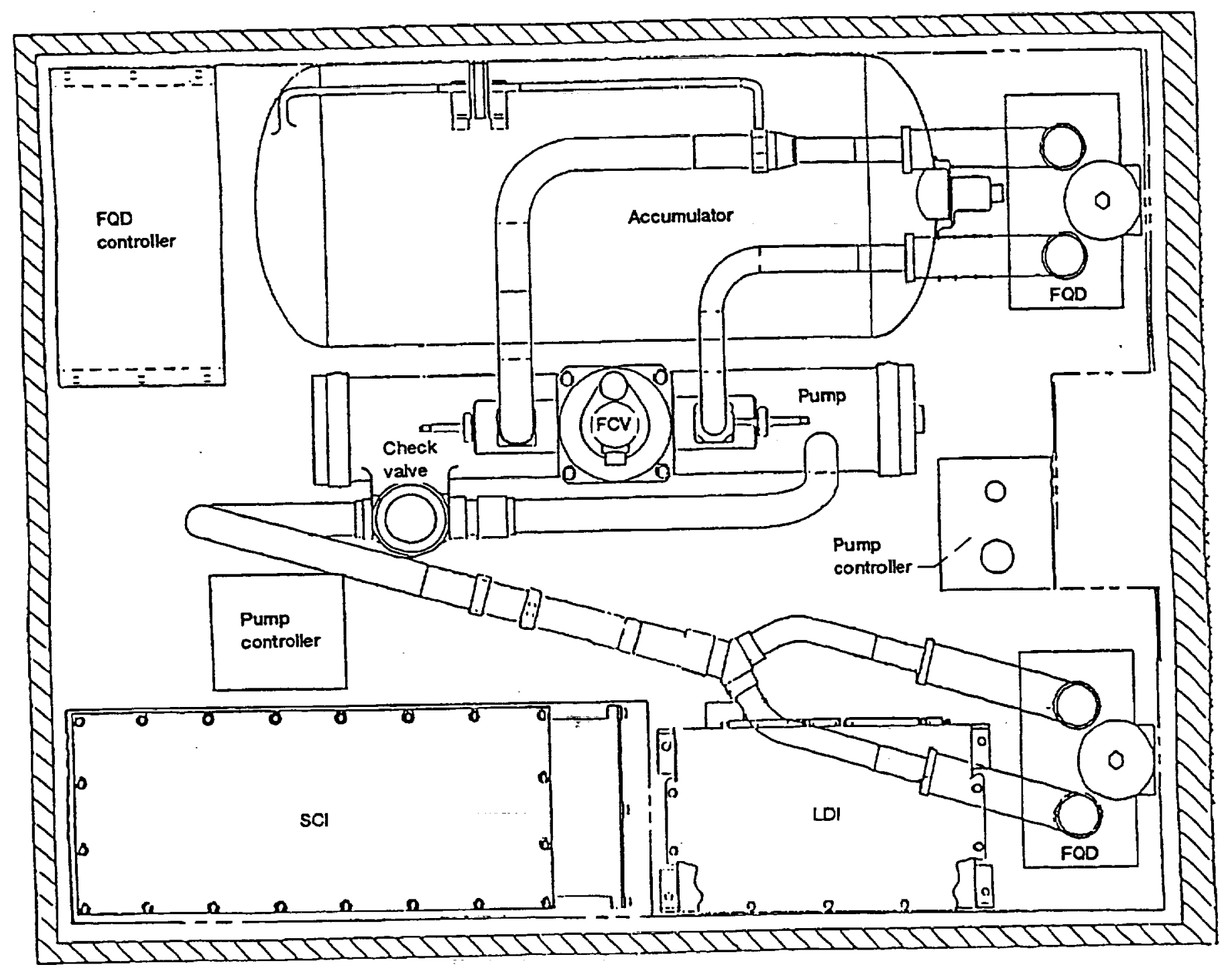

Figure 6.- Pump and flow control subassembly (PFCS). (Drawing courtesy of United Technologies Corporation.) 


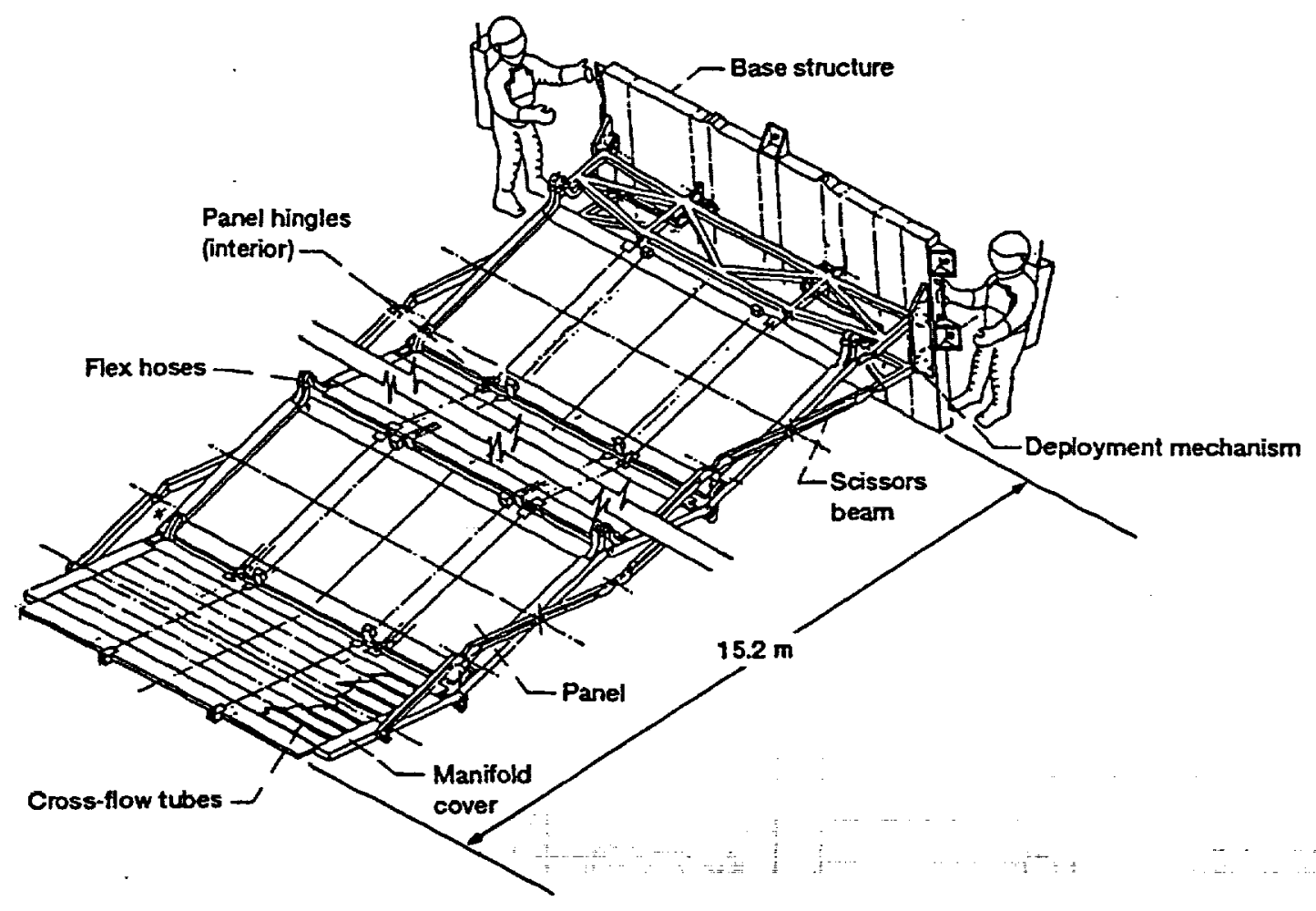

(a) Deployed position.

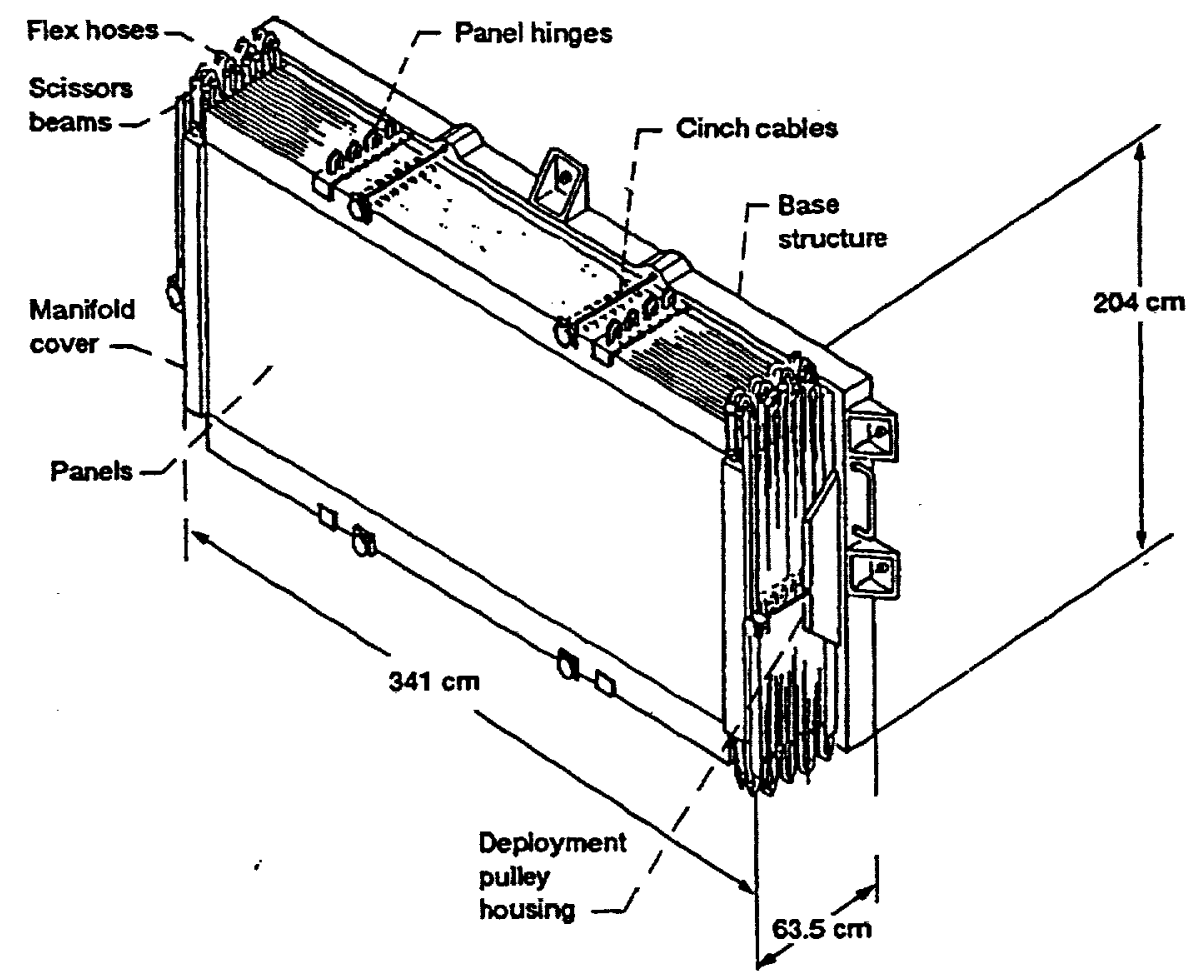

(b) Stowed position.

Figure 7.- Radiator subassembly. (Drawing courtesy of LTV Aerospace and Defense Company). 

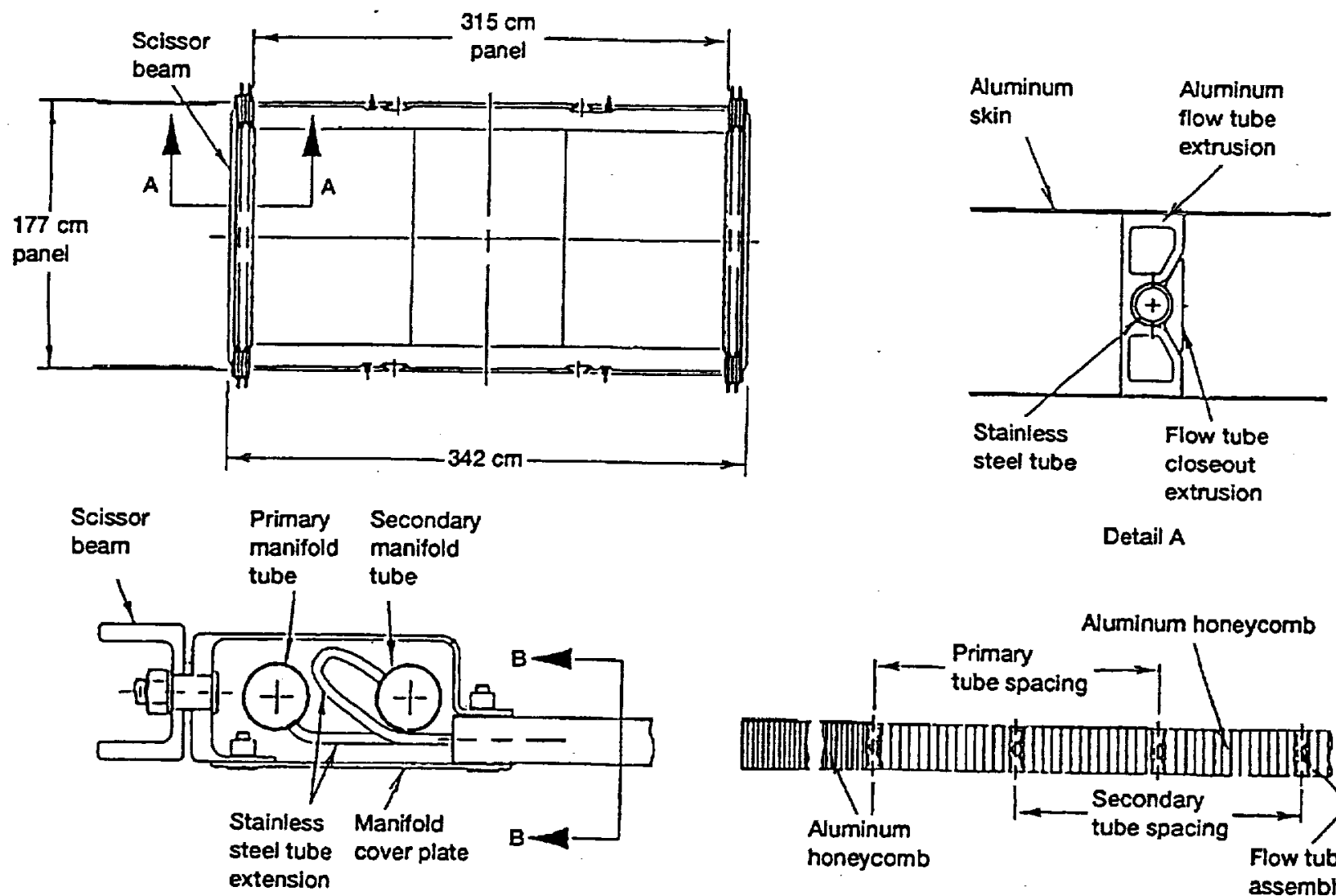

View A - A

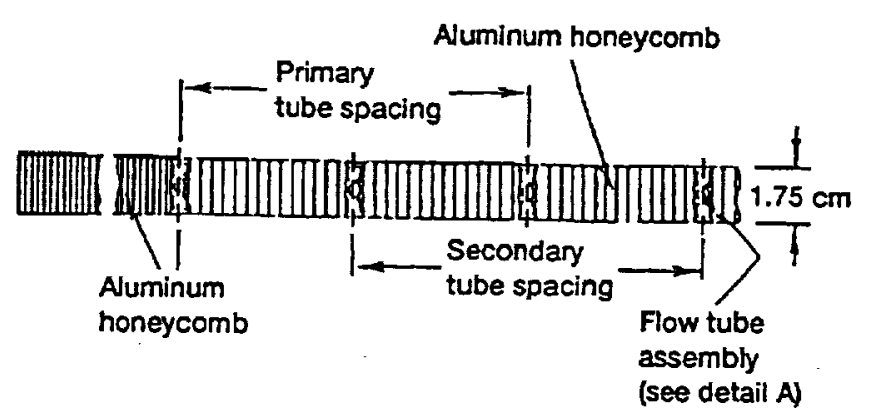

View B - B

Figure 8.- Radiator panel and manifold details (all dimensions approximate). (Drawing çourtesy of LTV Areospace and Defense Company.)

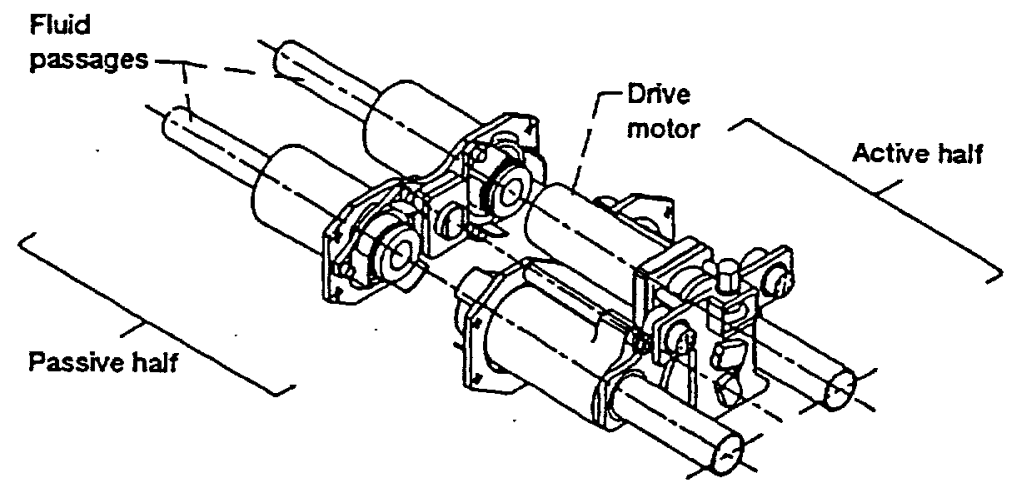

(a) Demated.

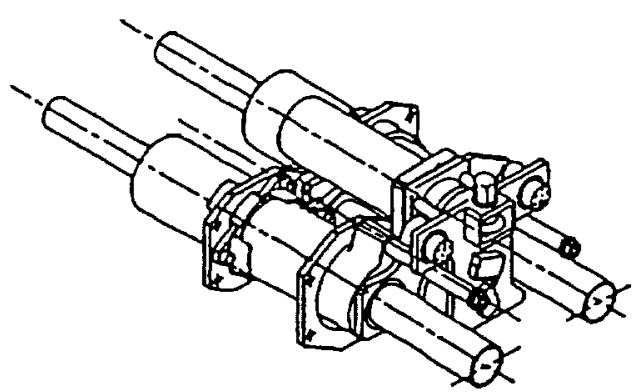

(b) Mated.

Figure 9.-Fluid quick disconnect coupling. (Drawing courtesy of Moog inc.) 


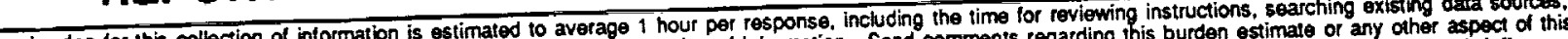
Public reporting burden lor inis collection of inlomaton is estind reviewing the collection of information. Send cornments regarding this burden estims and Reports. 1215 Jeffersen gathering and maintaining the daa needed, and corroducing this burden, to Washington Headquarers Senvices. Directorate ior Projed (0704-0188). Washington. DC 20503.

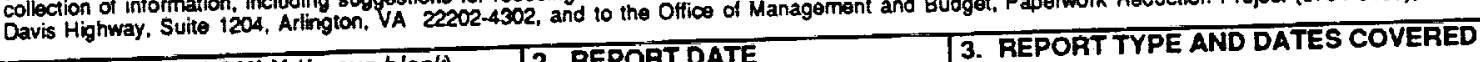

\begin{tabular}{l|l} 
1. AGENCY USE ONLY (Leave blank) & 2. REPORT DATE
\end{tabular}

\section{TITLE AND SUBTTLE}

January 1994

Technical Memorandum

Thermal Control System for Space Station Freedom Photovoltaic

Power Module

6. AUTHOR(S)

Thomas H. Hacha and Laura Howard

5. FUNDING NUMBERS

WU-474-46-10

7. PERFORMING ORGANIZATION NAME(S) AND ADDRESS(ES)

PERFORMING ORGANIZATION REPORT NUMBER

National Aeronautics and Space Administration

Lewis Research Center

E-7014

Cleveland, Ohio 44135-3191

9. SPONSORINGMONITORING AGENCY NAME(S) AND ADDRESSYES)

10. SPONSORINGMONITORING AGENCY REPORT NUMBER

National Aeronautics and Space Administration

NASA TM-105650

Washington, D.C. 20546-0001

11. SUPPLEMENTARY NOTES

Prepared for the 22nd Intemational Conference on Environmental Systems, sponsored by the Society of Automotive Engineer, Seattle,

Thomas H. Hacha, NASA Lewis Research Center and Laura Howard, Rockwell International

Washington, July 13-16, 1992. Tho Califomia 91303. Responsible person, Thomas H. Hacha, (216) 433-8319.

\begin{tabular}{l|l} 
Rocketdyne Division, Canoga Park, Calion & 12b. DISTRIBUTION CODE
\end{tabular}

12a. DISTRIBUTIONAVAILABILITY STATEMENT

Unclassified - Unlimited

Subject Categories 18, 20 and 34

13. ABSTRACT (Maximum 200 words)

The electric power for Space Station Freedom (SSF) is generated by the solar arrays of the photovoltaic power modules (PVM's) and conditioned, controlled, and distributed by a power management and distribution system. The PVM's are located outboard of the alpha gimbals of SSF. A single-phase thermal control system is being developed to provide thermal control of PVM electrical equipment and energy storage batteries. This system uses ammonia as the coolant and a direct-flow deployable radiator. This paper presents the description and development status of the PVM thermal control system.

14. SUBJECT TERMS

Photovoltaic; Electric power; Thermal; Space Station 13

16. PRICE CODE

\begin{tabular}{l|c|c} 
SECURTY CLASSIFICATION \\
$\begin{array}{c}\text { OF REPORT } \\
\text { Unclassified }\end{array}$ & $\begin{array}{c}\text { 18. SECURTY CLASSIFICATION } \\
\text { OF THIS PAGE } \\
\text { Unclassified }\end{array}$ & $\begin{array}{c}\text { 19. SECURTY CLASSIFICATION } \\
\text { OF ABSTRACT } \\
\text { Unclassified }\end{array}$ \\
\hline
\end{tabular}

